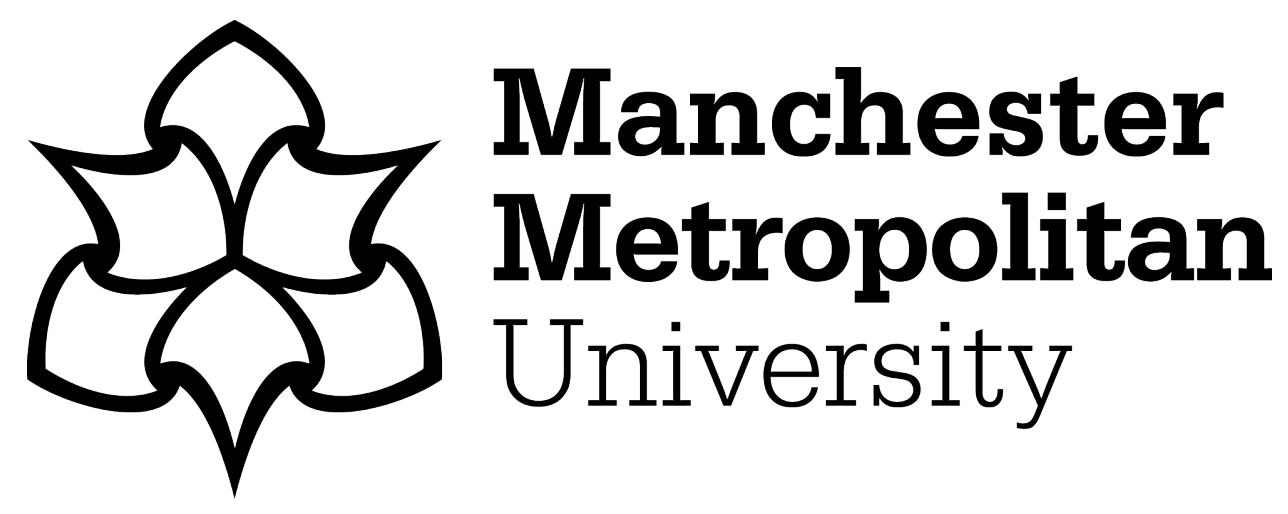

Xing, L, Liu, H and Zhou, JG (2020) Numerical study of the antibiotic transport and distribution in the Laizhou Bay, China. Environmental Science and Pollution Research, 27 (30). pp. 37760-37772. ISSN 0944-1344

Downloaded from: https://e-space.mmu.ac.uk/626144/

Version: Accepted Version

Publisher: Springer

DOI: https://doi.org/10.1007/s11356-020-09770-5

Please cite the published version 


\title{
Numerical study of the antibiotic transport and distribution in the Laizhou Bay, China
}

\author{
Liming Xing ${ }^{1} \cdot$ Haifei Liu $^{1}$ - Jian Guo Zhou ${ }^{2}$ \\ Received: 13 February 2020 / Revised: 21 April 2020 / Accepted: 16 June 2020 \\ (C) Springer-Verlag GmbH Germany, part of Springer Nature 2020
}

\begin{abstract}
A large number of antibiotic residues are discharged into aquatic environments due to the widespread use of antibiotics in daily life. After a series of processes in the water, the residues will potentially have adverse impacts on water ecosystem and human health. Therefore, it is critical for mediating the pollution to know how the antibiotics transport and distribute in the water. This study utilizes a two-dimensional lattice Boltzmann model to find out the transport and distribution of antibiotics in a highly polluted area, the Laizhou Bay in China. Furthermore, the model was used to simulate two scenarios in the Laizhou Bay, the antibiotics from sewage treatment plants and the contamination of mariculture. The simulated results show that the model as an effective tool can provide a useful basis for the management of antibiotics-related environmental issues in the Laizhou Bay.
\end{abstract}

Keywords Antibiotic $\cdot$ Aquatic environment $\cdot$ Laizhou Bay $\cdot$ Management $\cdot$ Lattice Boltzmann method

\section{Introduction}

Antibiotics have been used extensively in human and veterinary pharmaceuticals for the purpose of preventing or treating microbial infections since the discovery of penicillin in 1928 (Kümmerer 2009). It has been estimated that the annual usage of antibiotics in China is approximately 25,000 tons, accounting for a considerable proportion of global annual usage, which is between 100,000 and 200,000 tons (Kümmerer 2003). In addition, antibiotics are commonly used in mariculture, for instance, in shrimp farming (Holmström et al. 2003). Only a few antibiotic compounds are partially biodegraded in aquatic systems; most of them

Responsible Editor: Marcus Schulz

Haifei Liu

haifei.liu@bnu.edu.cn

Liming Xing

liming.xing@mail.bnu.edu.cn

Jian Guo Zhou

j.zhou@mmu.ac.uk

1 School of Environment, Beijing Normal University, Beijing, 100875, China

2 Department of Computing and Mathematics, Manchester Metropolitan University, Manchester, UK are residual. If antibiotic residues are not eliminated properly, then they can reach aquatic and terrestrial environments, where they can have detrimental effects (Kümmerer 2003; 2009) and will lead to antibiotic resistance among pathogens infecting cultured animals and humans. Therefore, antibiotics have been listed as a kind of emerging environmental contaminant due to their possible threats to ecosystems and human health (Liu and Wong 2013). Recently, increasing numbers of scholars have begun to study antibiotics in marine environments. They have found that the main sources of antibiotics are riverine inputs (Yang et al. 2014), sewage treatment plants ( $\mathrm{Li}$ et al. 2016) and mariculture (Holmström et al. 2003).

The Laizhou Bay $\left(37.65^{\circ} \mathrm{N}, 119.28^{\circ} \mathrm{E} \sim 37.68^{\circ} \mathrm{N}\right.$, $120.22^{\circ} \mathrm{E}$ ) is one of the three largest bays in the Bohai Sea, northern China (Fig. 1). The length of the coastline is $219.06 \mathrm{~km}$, and the total maritime area is $6966.93 \mathrm{~km}^{2}$. Owing to the influence of sand silting, the area with a water depth less than $10 \mathrm{~m}$ accounts for a large proportion of the sea area, and the deepest depth is $18 \mathrm{~m}$. Affected by terrain, the seawater along the west coast of the bay rotates anticlockwise and does clockwise at the east coast. The dominant tidal constituent at the Laizhou Bay is semidiurnal M2 from the outside Yellow River Estuary (Xu and Jiang 1990; Lv et al. 2017). The tide is mainly clockwise rotating currents affected by the topography, and rising tide direction is northeast-southwest as well as falling tide direction is 
northwest-southeast. The bay is an important locality for fisheries and the salt industry, providing substantial amounts of aquatic products. With increasing industrialization and urbanization recently in the Laizhou Bay, the aquaculture and mariculture of the Bay have prospered. Along the coastline, there are more than 20 rivers flowing into the bay. Therefore, the antibiotic residues from sewage treatment plants and industrial activities unavoidably flow into the bay through riverine inputs. At the same time, these antibiotics give rise to ecological crises in the marine environment. Thus, it is essential to understand the transport and distribution of antibiotics in the Laizhou Bay. However, pertinent discussions have been limited to date, especially for the transport of antibiotics, which is detrimental for controlling antibiotics contamination in the Laizhou Bay.

Antibiotics in aquatic environments are multifarious, and their concentrations are low at the $\mathrm{ng} / \mathrm{L} \sim \mathrm{ug} / \mathrm{L}$ level (Min and Lu 2013). Consequently, many researchers focus on empirical and experimental methods in study related to the distribution of antibiotics; they use solid phase extraction to pretreat the samples and then detect and analyze the antibiotics using liquid chromatography tandem mass spectrometry (LC-MS/MS) technology. Since then, the use of evolutionary LC-MS/MS technologies has been increased (Zhang et al. 2012; Du et al. 2015). Furthermore, with the development of computational technology, numerical simulation as a promising calculation method has been applied in these fields. For instance, based on the Fugacity models proposed by Chi and Yang (2012), which are useful for investigating the fate of chemicals in the environment, Zhang et al. (2015) and Chen et al. (2018) studied the fate of antibiotics in the water. Gothwal and Thatikonda (2018) used a mathematical model to investigate transport of fluoroquinolones and its resistant bacteria in the riverine environment.

In this paper, we solved shallow water equations and the advection-diffusion equation together with a secondorder treatment for the dry-wet interface of shallow water using an innovative numerical method, the two-relaxationtime lattice Boltzmann method (TRT-LBM), to simulate the transport and distribution of antibiotics in the Laizhou Bay. Knowledge on this study would benefit the environmental management of the Laizhou Bay, particularly by providing a contaminative estimation of the antibiotics resulting from the effects of sewage treatment plants and mariculture. It would also have hints on the policy making in antibiotic pollution control in the Laizhou Bay.

\section{Methodology}

Compared with the traditional numerical methods, the lattice Boltzmann models can describe the microscopic behavior of particles in a simpler form and accurately reflect the movement of fluid at the macroscopic level. Meanwhile, easier programming and parallel operations can be conducted. Moreover, the two-relaxation-time method is preferable in terms of simplicity and computational time, and also benefits from additional collision freedom to improve stability and possesses higher-order accuracy and precision of boundary conditions (Ginzburg 2005; Ginzburg et al. 2008). Thus, the TRT-LBM is applied to the shallow water equations for a hydrodynamic model and to the advection-diffusion equation for an advection-diffusion reaction (ADR) model, respectively.

In order to verify the proposed model, relevant field measurements of antibiotics in the Laizhou Bay are needed. We obtain the experimental data from the previous study (Zhang et al. 2012). Four types of antibiotics were selected including erythromycin (ETM), enoxacin (ENO), trimethoprim (TMP) and sulfamethoxazole (SMX) in this study. The sample sites are shown as Fig. 1 including the estuaries of nine rivers except for the Yellow River and the other three sampling sites (P1, P2, and P3) in the bay. The samples were collected at $0-50 \mathrm{~cm}$ below the water surface using stainless steel buckets and were immediately transferred to 5-1 pre-cleaned amber glass bottles. All the samples were kept at $4{ }^{\circ} \mathrm{C}$ before the post treatment and then analyzed by an optimized high performance liquid chromatography-electrospray ionization tandem mass spectrometry with multiple reaction monitoring in the laboratory to obtain the sample concentrations.

\section{Hydrodynamic model}

The two-dimensional (2D) shallow water equations including the continuity equation and momentum equation are written as

$$
\left\{\begin{array}{l}
\frac{\partial h}{\partial t}+\frac{\partial\left(h u_{j}\right)}{\partial x_{j}}=0, \\
\frac{\partial\left(h u_{i}\right)}{\partial t}+\frac{\partial\left(h u_{i} u_{j}\right)}{\partial x_{j}}=-g \frac{\partial}{\partial x_{i}}\left(\frac{h^{2}}{2}\right)+v \frac{\partial^{2}\left(h u_{i}\right)}{\partial x_{j} \partial x_{j}}-g \bar{h} \frac{\partial Z_{b}}{\partial x_{j}}+F_{i},
\end{array}\right.
$$

where the subscripts $i$ and $j$ are the space direction indices following the Einstein summation convention; $x_{j}$ is the Cartesian coordinate, taking $x$ and $y$ in turn; and $u_{j}$ is the velocity component, which takes $u$ and $v$, corresponding to that in the $x$ and $y$ directions, respectively. $h$ is the water depth; $t$ is time; $v$ is the eddy viscosity; $Z_{b}$ is the bed elevation above the datum (mean sea surface of the Yellow Sea); and $F_{i}$ is the force term contains the bed shear stress $\tau_{b i}$ in the present study, which is calculated by

$\tau_{b i}=\rho C_{b} u_{i} \sqrt{u_{j} u_{j}}$, 

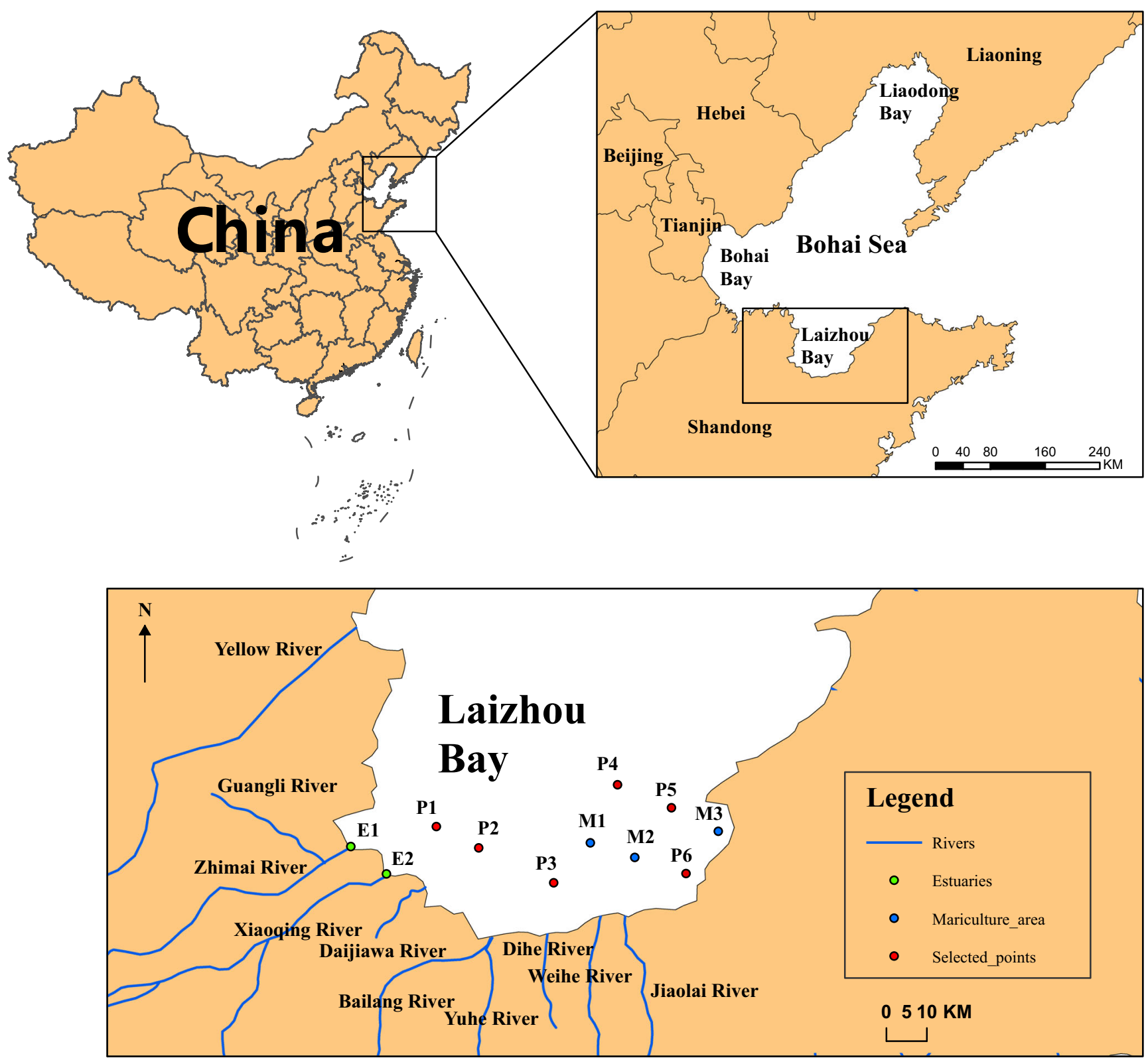

Fig. 1 Map of the Laizhou Bay

in which $C_{b}$ is the bed friction coefficient, which is calculated by $C_{b}=g / C_{z}^{2}$, where $C_{z}$ is the Chezy coefficient given by the Manning coefficient $n_{b}$,

$C_{z}=h^{\frac{1}{6}} / n_{b}$.

There are two relaxation times in the TRT-LBM, including symmetric relaxation time $\tau_{s}$ and asymmetric one $\tau_{a}$. Peng et al. (2016) used a TRT-LBM with a two-dimensional nine-speed square lattice (D2Q9) for shallow water equations. The study revealed that different relationships of the two relaxation times would influence the stability of the TRT-LBM, and the combination of $\left(\tau_{s}-0.5\right)\left(\tau_{a}-0.5\right)=1 / 12$ was recommended. If $\tau_{s}=$ $\tau_{a}$, the TRT-LBM equation is reduced to an BGK-LBM equation. Ginzburg (2005) indicated that in hydrodynamic momentum conservation equations (such as shallow water equations), $\tau_{s}$ depends on the kinematic viscosity and $\tau_{a}$ can be calculated from the combination, whereas in the advection-diffusion equation, $\tau_{a}$ depends on the dispersion coefficient and $\tau_{s}$ can be obtained from the combination. The free terms can be determined from the aforementioned combination. In view of the D2Q9 model, the lattice 
Boltzmann equation following the TRT method for shallow water equations is

$$
\begin{gathered}
f_{\alpha}\left(x+e_{\alpha} \Delta t, t+\Delta t\right)-f_{\alpha}(x, t)=-\frac{1}{\tau_{s}}\left[f_{\alpha}^{s}(x, t)-f_{\alpha}^{s e q}(x, t)\right] \\
-\frac{1}{\tau_{a}}\left[f_{\alpha}^{a}(x, t)-f_{\alpha}^{a e q}(x, t)\right]-3 \Delta t \omega_{\alpha} e_{\alpha j} \frac{g h}{e^{2}} \frac{\partial Z_{b}}{\partial x_{j}}+\Delta t F_{\alpha},
\end{gathered}
$$

where $\bar{h}=0.5\left[h\left(x+e_{\alpha} \Delta t, t+\Delta t\right)+h(x, t)\right] ; \omega_{\alpha}$ is the weight factor: $\omega_{\alpha}=4 / 9$ for $\alpha=0 ; \omega_{\alpha}=1 / 9$ for $\alpha=1,3,5$, and 7; and $\omega_{\alpha}=1 / 36$ for $\alpha=2,4,6$, and $8 ; f_{\alpha}$ is the distribution function of a particle; $f_{\alpha}^{s}$ and $f_{\alpha}^{s e q}$ are the symmetric parts of the particle distribution function and equilibrium distribution function, respectively; and $f_{\alpha}^{a}$ and $f_{\alpha}^{a e q}$ are the asymmetric parts of the particle distribution function and equilibrium distribution function, respectively. These four terms can be calculated from the following equations (Peng et al. 2016):

$f_{\alpha}^{s}=\frac{f_{\alpha}+f_{\bar{\alpha}}}{2}$,

$f_{\alpha}^{a}=\frac{f_{\alpha}-f_{\bar{\alpha}}}{2}$,

$f_{\alpha}^{s e q}=\frac{f_{\alpha}^{e q}+f_{\bar{\alpha}}^{e q}}{2}$

$f_{\alpha}^{a e q}=\frac{f_{\alpha}^{e q}-f_{\bar{\alpha}}^{e q}}{2}$,

in which $\bar{\alpha}$ is the opposite direction of $\alpha$, and $f_{\alpha}^{e q}$ and $f_{\bar{\alpha}}^{e q}$ are the corresponding distribution function and equilibrium distribution function, respectively. The external force term $F_{\alpha}$ can be written as

$F_{\alpha}=-3 \omega_{\alpha} \frac{1}{e^{2}} e_{\alpha i} \frac{\tau_{b i}}{\rho}$.

In this study, the centered scheme of force term is used to keep (4) in the second-order accuracy for obtaining macroscopic continuity and momentum equations.

For the D2Q9 lattice shown in Fig. 2, each particle moves one lattice at its velocity only along the eight links indicated

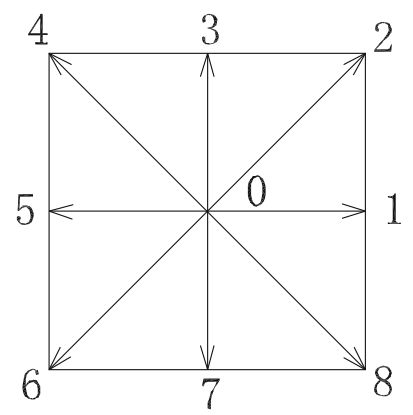

Fig. 2 D2Q9 lattice by $1-8 ; 0$ indicates the rest particle with a speed of zero. The particle velocity is

$e_{\alpha}= \begin{cases}(0,0) & \alpha=0, \\ e\left[\cos \frac{(\alpha-1) \pi}{4}, \sin \frac{(\alpha-1) \pi}{4}\right] & \alpha=1,3,5,7, \\ \sqrt{2} e\left[\cos \frac{(\alpha-1) \pi}{4}, \sin \frac{(\alpha-1) \pi}{4}\right] & \alpha=2,4,6,8,\end{cases}$

where $e=\Delta x / \Delta t ; \Delta t$ is the time step; and $\Delta x$ is the lattice size.

In the LBM, it is essential to determine a suitable local equilibrium distribution function $f_{\alpha}^{e q}$ (Zhou 2004), which is expressed for the shallow water equations as

$f_{\alpha}^{e q}= \begin{cases}h-\frac{5 g h^{2}}{6 e^{2}}-\frac{2 h}{3 e^{2}} u_{i} u_{i} & \alpha=0, \\ \frac{g h^{2}}{6 e^{2}}+\frac{h}{3 e^{2}} e_{\alpha i} u_{i}+\frac{h}{2 e^{4}} e_{\alpha i} e_{\alpha j} u_{i} u_{j}-\frac{h}{6 e^{2}} u_{i} u_{i} & \alpha=1,3,5,7, \\ \frac{g h^{2}}{24 e^{2}}+\frac{h}{12 e^{2}} e_{\alpha i} u_{i}+\frac{h}{8 e^{4}} e_{\alpha i} e_{\alpha j} u_{i} u_{j}-\frac{h}{24 e^{2}} u_{i} u_{i} & \alpha=2,4,6,8 .\end{cases}$

As a result, the macroscopic terms of water depth $(h)$ and velocities $\left(u_{i}\right)$ can be calculated as

$h=\sum_{\alpha} f_{\alpha}$,

$u_{i}=\frac{1}{h} \sum_{\alpha} e_{\alpha i} f_{\alpha}$

\section{ADR model}

After obtaining the $h$ and $u_{i}$ by means of the hydrodynamic model, antibiotic concentrations can be calculated using the ADR model.

The advection and diffusion process for pollutants in a 2D fluid is very complex. In general, the processes of solute diffusion, transport and degradation can be described by the $2 \mathrm{D}$ advection-diffusion equation,

$\frac{\partial(h c)}{\partial t}+\frac{\partial\left(h c u_{i}\right)}{\partial x_{i}}=\frac{\partial}{\partial x_{i}}\left[K_{i j} \frac{\partial(h c)}{\partial x_{i}}\right]+S_{c}$,

in which $c$ is the depth-averaged solute concentration; $S_{c}$ is a source or sink term, $S_{c}=h c K_{d}$ in this work, where $K_{d}$ is the degradation coefficient; and $K_{i j}$ is the dispersion coefficient.

In the ADR model discretized by the 2D TRT-LBM, the LBM equation, can be expressed as

$$
\begin{aligned}
g_{\alpha}\left(x+s_{\alpha} \Delta t, t+\Delta t\right)-g_{\alpha}(x, t) \\
=-\frac{1}{\tau_{s}}\left[g_{\alpha}^{s}(x, t)-g_{\alpha}^{s e q}(x, t)\right]-\frac{1}{\tau_{a}}\left[g_{\alpha}^{a}(x, t)\right. \\
\left.\quad-g_{\alpha}^{a e q}(x, t)\right]+\frac{S_{c}}{b} \Delta t,
\end{aligned}
$$


where $b$ is the number of the particle velocity (Zhou 2011), $b=9$ in this study which indicates the first-order accuracy due to the treatment of the source term with $1 / b$ isotropically; $g_{\alpha}$ is the particle distribution function of the solute; $g_{\alpha}^{s}$ and $g_{\alpha}^{\text {seq }}$ are the symmetric parts of the particle distribution function and equilibrium distribution function, respectively; and $g_{\alpha}^{a}$ and $g_{\alpha}^{a e q}$ are the asymmetric parts of the particle distribution function and equilibrium distribution function, respectively. These components can be determined by equations similar to Eqs. (5)-(8) in the hydrodynamic model.

Only a properly defined local equilibrium distribution function can lead to the concentration solutions. Thus, the following $g_{\alpha}^{e q}$ is proposed (Zhou 2011):

$$
g_{\alpha}^{e q}=\left\{\begin{array}{lc}
\left(1-\frac{\lambda_{y y} e_{x}^{2}+\lambda_{x x} e_{y}^{2}}{e_{x} e_{y}}\right) h c & \alpha=0, \\
\left(\frac{1}{2} \frac{e_{y}}{e_{x}} \lambda_{x x}+\frac{u_{x}}{4 e_{\alpha x}}\right) h c & \alpha=1,5, \\
\left(\frac{1}{2} \frac{e_{x}}{e_{y}} \lambda_{y y}+\frac{u_{y}}{4 e_{\alpha y}}\right) h c & \alpha=3,7, \\
\left(\frac{1}{4} \frac{e_{x} e_{y}}{e_{\alpha x} e_{\alpha y}} \lambda_{x y}+\frac{u_{i}}{8 e_{\alpha i}}\right) h c & \alpha=2,4,6,8,
\end{array}\right.
$$

where $\lambda_{i j}$ is the nondimensional coefficient defined by

$$
\lambda_{i j}=\frac{K_{i j}}{\Delta t\left(\tau_{a}-\frac{1}{2}\right) e_{i} e_{j}} .
$$

Therefore, the concentration $c$ at a macroscopic level is calculated from the particle distribution function governed by Eq. (15) as

$c=\frac{1}{h} \sum_{\alpha} g_{\alpha}$

Since the LBM-TRT only involves collision items, using the central scheme for source and sink items has the secondorder accuracy (Zhou 2011).

\section{Degradation of antibiotics}

Degradation is an important metabolic process for environmental antibiotics, and antibiotics are likely to be degraded through multiple processes in aquatic systems owing to the abundant illumination of the water surface and rapid growth rate of microorganisms (Hallingsørensen and Jørgensen 2000) such as hydrolysis, photolysis and biodegradation (Shi et al. 2016). Hydrolysis is mainly affected by a pH (Min and Lu 2013). Photolytic degradation is slow, thereby leading to a longer residual time in the environment (Meng et al. 2015). Biodegradation is an important degradation process, and it varies among antibiotics and environmental media (Hallingsørensen et al. 1998).

Apart from the four types of antibiotics with high detection rates (ETM, ENO, TMP, SMX), additionally, ciprofloxacin (CPFX) is included in this work because of its common use in mariculture. Considering geographic location, $\mathrm{pH}$ values $(\mathrm{pH}=7.99 \sim 8.9)$ and the climatic conditions at the sample site, degradation rates $\left(D_{r}\right)$ are determined and listed in Table 1. Notably, the degradation of TMP and SMX is mainly via photolysis and therefore can be represented by the photolysis rate constant $\left(k_{o k s}\right)$ and half-life $\left(t_{\frac{1}{2}}\right)$. The degradation processes can be calculated through Eqs. (19) and (20):

$t_{\frac{1}{2}}=\ln 2 / k_{o k s}$,

$C(t)=C_{0}\left(\frac{1}{2}\right)^{t / t} \frac{1}{2}$

\section{Model validation}

\section{Hydrodynamic model validation}

\section{Parameter setting}

The original topographic data is obtained from China Hydrography Official. After post-treatment calibration due

Table 1 The degradation details of the selected antibiotics

\begin{tabular}{llll}
\hline Antibiotic & Degradation parameter & Condition & Reference \\
\hline ETM & $D_{r}=0.82 \% /$ day & $\mathrm{pH} \approx 8.38$ & Xiao et al. (2008) \\
ENO & $D_{r}=7.95 \% /$ day & - & Zhang (2013) \\
TMP & $k_{o k s}=0.06 / \mathrm{h}$ & - & Ryan et al. (2011) \\
SMX & $t_{\frac{1}{2}}=18.48 \mathrm{~h}$ & Autumn, $40^{\circ} \mathrm{N}$ & Andreozzi et al. (2003) \\
CPFX & $D_{r 1}=3.67 \% / \mathrm{h}$ & Illumination & Zhang (2016) \\
& $(t<6 h)$ & & \\
& $D_{r 2}=0.3 \% / \mathrm{h}$ & & \\
& $(t \geq 6 \mathrm{~h})$ & & \\
\end{tabular}


to the inaccuracy resulting from the sand dredging and landreclamation in some areas, AcrGIS is used to generate the terrain of the Laizhou Bay by interpolation and fishnet. Based on the topographic data, the initial still water level is shown as Fig. 3. The study domain is divided into $140 \times 230$ uniform meshes with a grid size of $\Delta x=\Delta y=460 \mathrm{~m}$. $\Delta t$ is set to $4 s$ according to $\Delta x / \Delta t \gg u$, which satisfies the model stability and accuracy requirements. $\tau_{s}=0.7$ in the hydrodynamic model, and $\tau_{a} \approx 0.92$, which is calculated from $\left(\tau_{s}-0.5\right)\left(\tau_{a}-0.5\right)=1 / 12$. Manning coefficient $n_{b}=0.01 \mathrm{~m}^{1 / 3} / \mathrm{s}$.

\section{Boundary conditions}

The outer sea boundary is controlled by the tidal function of time series, which is repeated every $12 \mathrm{~h}$. And accurate tidal data which have been calibrated by the previous research (Liu et al. 2017). The coastline of the bay is treated by second-order dry-wet boundary conditions (see details in Appendix).

\section{Validation}

Figure 4 is the ebb peak and flood peak of the Laizhou Bay. At ebb tide in Laizhou Bay (Fig. 4a), seawater flows out towards bay mouth, and the flow direction is basically from east to north. The maximum velocity is approximate $1 \mathrm{~m} / \mathrm{s}$ located at the northwest of the bay mouth as well as the minimum value is along the coastline with $0.1 \mathrm{~m} / \mathrm{s}$. At flood tide (Fig. 4b), seawater rushes to the bay, and the flow direction is basically from south to southwest. The maximum velocity is about $0.9 \mathrm{~m} / \mathrm{s}$ and the minimum value is also along the coastline. Compared with the results of Lv et al. (2017) (Fig. 5), the difference of flow directions in the upper right corner comes from the difference in processing of boundary conditions and has negligible effects on the pollutant area in this study. Therefore, the proposed hydrodynamic model was proved to be able to generate the reliable results.

\section{ADR model validation}

Based on Zhang et al. (2012), antibiotic transmission is simulated separately for ETM, ENO, TMP, and SMX with the proposed model. Then, the vertically integrated concentrations from the model simulations and experimental data from the near-shore locations P1, P2, and P3 (Fig. 1) are compared for the four selected antibiotics to verify the model.

\section{Parameter setting}

Based on the parameter setting and results of the hydrodynamic model, in the ADR model, $\tau_{a}=1.5$ and $\tau_{s} \approx 0.58$ according to the same relationship. Isotropic diffusion is assumed, and the dispersion coefficients are $K_{x x}=K_{y y}=10 \mathrm{~m}^{2} / \mathrm{s}$ and $K_{x y}=K_{x y}=0$ based on model stability and the fitting of experimental data. It should be noted that D2Q5 model is also competent for isotropic diffusion problems. The antibiotics pollution is treated as a point source in the boundary of the model, and the sources of these antibiotics are shown in Table 2.

\section{Validation}

Figure 6 shows the fractional errors between the simulated results and experimental data for different antibiotics and locations after $42 \mathrm{~h}$. Considering the samples are collected
Fig. 3 The water depth in the Laizhou Bay

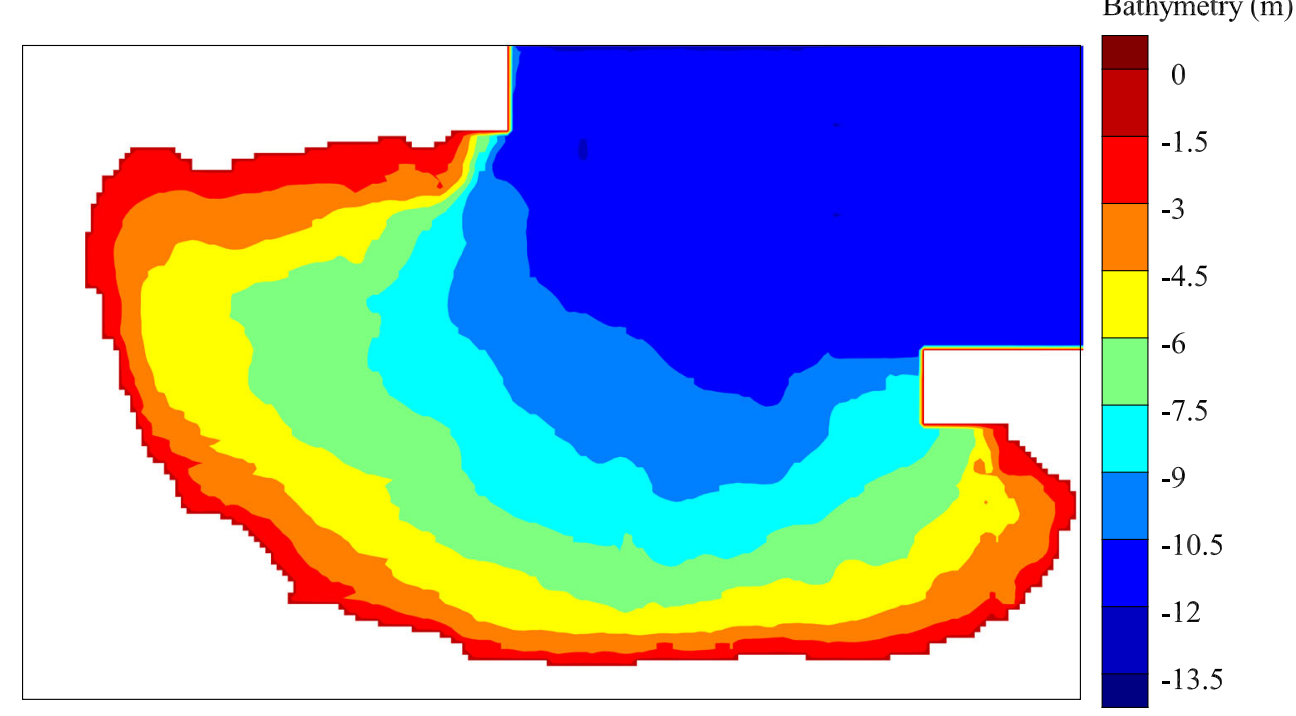




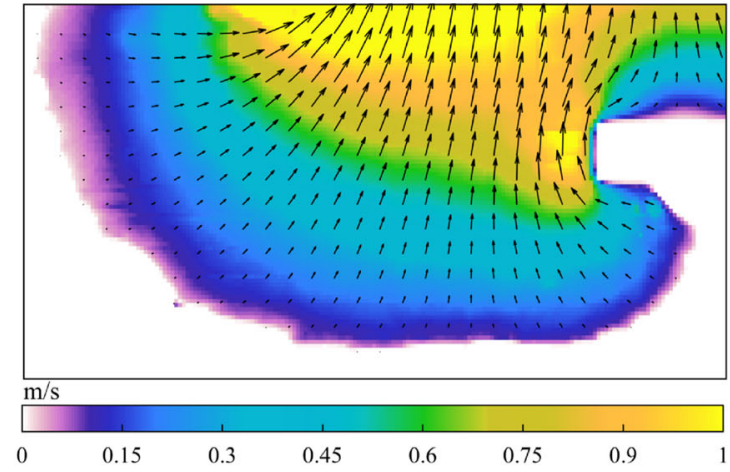

(a) ebb peak

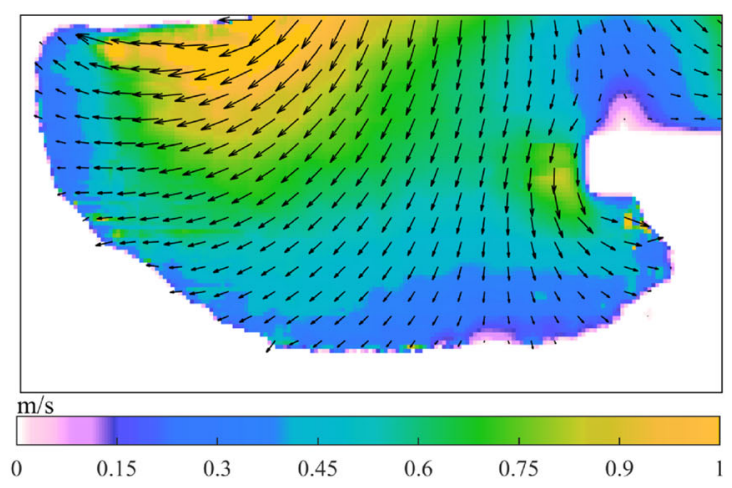

(b) flood peak

Fig. 4 The ebb peak and flood peak of the Laizhou bay

at about $50 \mathrm{~cm}$ below the water surface, it inevitably involves some errors in validate the depth-averaged model. Therefore, the results obtained by the proposed model are sufficiently accurate for dealing with the transport of antibiotics. Moreover, the simulation results highlight the concentrations of four antibiotics in the near-shore area, even up to hundreds of ng/L. For instance, the concentration of TMP at P1 (see Fig. 1) is $338.923 \mathrm{ng} / \mathrm{L}$. In view of the high density of human activities and the main river flows, these near-shore antibiotic concentrations illustrate the prominent effects of riverine inputs on the marine environment.

\section{Sensitivity analysis}

The relaxation time $(\tau)$ has a profound influence on the dynamics. Therefore, the sensitivity test of $\tau$ was performed in this study. The numerical simulations of ETM transport with various combinations of $\tau$ in hydrodynamics and the ADR models were conducted (Fig. 7). In the test, $\tau_{H s}$ and $\tau_{A D a}\left(\tau_{H s}\right.$ and $\tau_{H a}$ are the symmetric and asymmetric relaxation times in the hydrodynamic model, respectively, and $\tau_{A D s}$ and $\tau_{A D a}$ are the ones in the ADR model) are given with different values, where $\tau_{H a}$ and $\tau_{A D s}$ can be calculated from the formula $\left(\tau_{s}-0.5\right)\left(\tau_{a}-0.5\right)=1 / 12$. In this case, the simulated results in the ADR model are more sensitive than the hydrodynamic model to the $\tau$ value. When $\tau_{H s}=0.7, \tau_{H a}=0.92, \tau_{A D a}=1.5$ and $\tau_{A D s}=0.58$, the concentrations of ETM agree with the experimental values. When $\tau_{H s}$ is reduced by $10 \%$ and $20 \%$, the concentrations of ETM evenly decrease $0.0013 \%$ and $0.0004 \%$. While $\tau_{H s}$ is increased by $10 \%$ and $20 \%$, it leads to an average increase of $0.0003 \%$ and $0.0005 \%$ in the simulations, respectively. Likewise, when $\tau_{A D a}$ is reduced by the referred values, the concentrations decrease $27.67 \%$ and $14.83 \%$. The increase of $\tau_{A D a}$ at the same rate give rise to $24.94 \%$ and $23.72 \%$ increase on average, respectively.

The dispersion coefficients $K_{i j}$ are varied with different solutes and external environmental factors. Therefore, it is necessary to perform the sensitivity test of $K_{i j}$ considering the model stability and fitting of experimental data. Figure 8 shows that the simulation results of ETM concentrations are highly sensitive to $K_{i j}$. When $K_{x x}=K_{y y}=10 \mathrm{~m}^{2} / \mathrm{s}$, the simulation results are basically consistent with the experimental data. When $K_{x x}$ and $K_{y y}$ are reduced by $10 \%$ and $20 \%$, the simulation results decrease $10.53 \%$ and

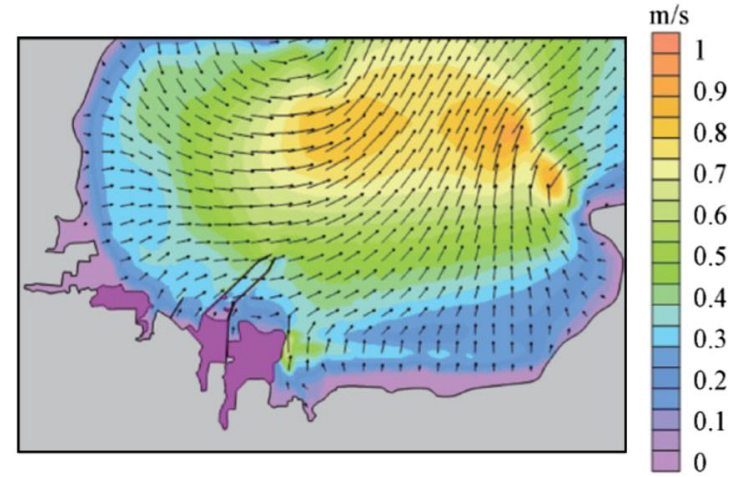

(a) ebb peak

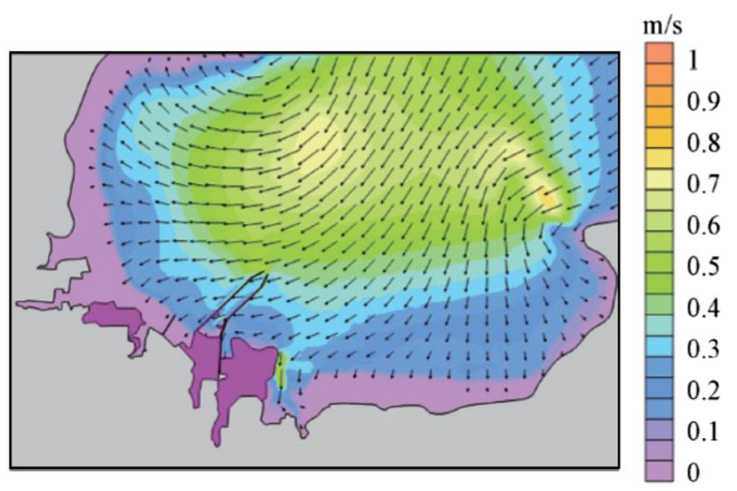

(b) flood peak

Fig. 5 The comparison results extracted from Lv et al. (2017) 
Table 2 Antibiotic concentrations (ng/L) in the discharging rivers (Zhang et al. 2012)

\begin{tabular}{|c|c|c|c|c|c|}
\hline Estuary & Geographic coordinates & ETM & ENO & TMP & SMX \\
\hline Xiaoqing River & $119^{\circ} 00.157^{\prime} \mathrm{E}, 37^{\circ} 17.210^{\prime} \mathrm{N}$ & 182 & 171 & 3558 & 92.9 \\
\hline Guangli River & $118^{\circ} 56.841^{\prime} \mathrm{E}, 37^{\circ} 21.437^{\prime} \mathrm{N}$ & 148 & 207 & 3551 & 83.5 \\
\hline Bailang River & $119^{\circ} 12.557^{\prime} \mathrm{E}, 37^{\circ} 11.154^{\prime} \mathrm{N}$ & 34.8 & 216 & 76.7 & 194 \\
\hline Dihe River & $119^{\circ} 19.205^{\prime} \mathrm{E}, 37^{\circ} 07.753^{\prime} \mathrm{N}$ & 78.6 & 56.9 & 54.5 & 31.3 \\
\hline Yuhe River & $119^{\circ} 17.180^{\prime} \mathrm{E}, 37^{\circ} 07.787^{\prime} \mathrm{N}$ & 19.5 & 28.9 & 1.5 & 10.4 \\
\hline Zhiman River & $118^{\circ} 56.841^{\prime} \mathrm{E}, 37^{\circ} 21.437^{\prime} \mathrm{N}$ & 11.6 & 151 & 8.4 & 9.9 \\
\hline Jiaolai River & $119^{\circ} 35.177^{\prime} \mathrm{E}, 37^{\circ} 06.866^{\prime} \mathrm{N}$ & 3.7 & 160 & 2.7 & 3.5 \\
\hline Weihe River & $119^{\circ} 29.528^{\prime}$ E, $37^{\circ} 07.219^{\prime} \mathrm{N}$ & 0.72 & 89.7 & 5.4 & 0.68 \\
\hline Dajiawa River & $119^{\circ} 03.886^{\prime} \mathrm{E}, 37^{\circ} 14.964^{\prime} \mathrm{N}$ & 9.2 & 0 & 990 & 527 \\
\hline
\end{tabular}

$18.84 \%$, respectively. While $K_{x x}$ and $K_{y y}$ are raised by $10 \%$ and $20 \%$, it also leads to an average increase of $15.43 \%$ and $36.13 \%$ in the simulation, respectively.

\section{Scenario simulations}

\section{Scenario 1: the discharge from sewage treatment plants}

At present, domestic sewage treatment plants do not regard antibiotics as target pollutants, due to the lack of legislation. Thus, antibiotics are inevitably discharged into the marine environment. In general, the antibiotic concentrations in surface water are at the $\mathrm{ng} / \mathrm{L}$ level, but in the areas near point-pollution sources, such as sewage treatment plants and sewage outlets of centralized livestock farms and antibiotic production factories, the concentrations are very high and can reach $14 \mathrm{mg} / \mathrm{L}$ (Fick et al. 2010). There are two sewage treatment plants near the Guangli River and Xiaoqing River in Shandong Province. Therefore, the excessive release of ENO (the main antibiotic in the sewage) at $100 \mathrm{mg} / \mathrm{L}$ was assumed to occur in the estuaries of the Guangli River (E1) and Xiaoqing River (E2) (see Fig. 1).

\section{Scenario 2: the contamination from mariculture}

Zou et al. (2011) found that antibiotics are commonly used in aquaculture, even in nursery feeding. Moreover, misusing antibiotics can also lead to the contamination of aquatic environments. CPFX is popular in marine areas as an effective kind of antibiotic. $\mathrm{pH}$ has a considerable impact on the degradation of CPFX, and the degradation occurs only with illumination (Torniainen et al. 1997; Zhang 2016). The implemented degradation rate of CPFX is shown in Table 1. During the next five years, the annual production of
Fig. 6 Comparison of simulation results and experimental data $(\mathrm{ng} / \mathrm{L})$

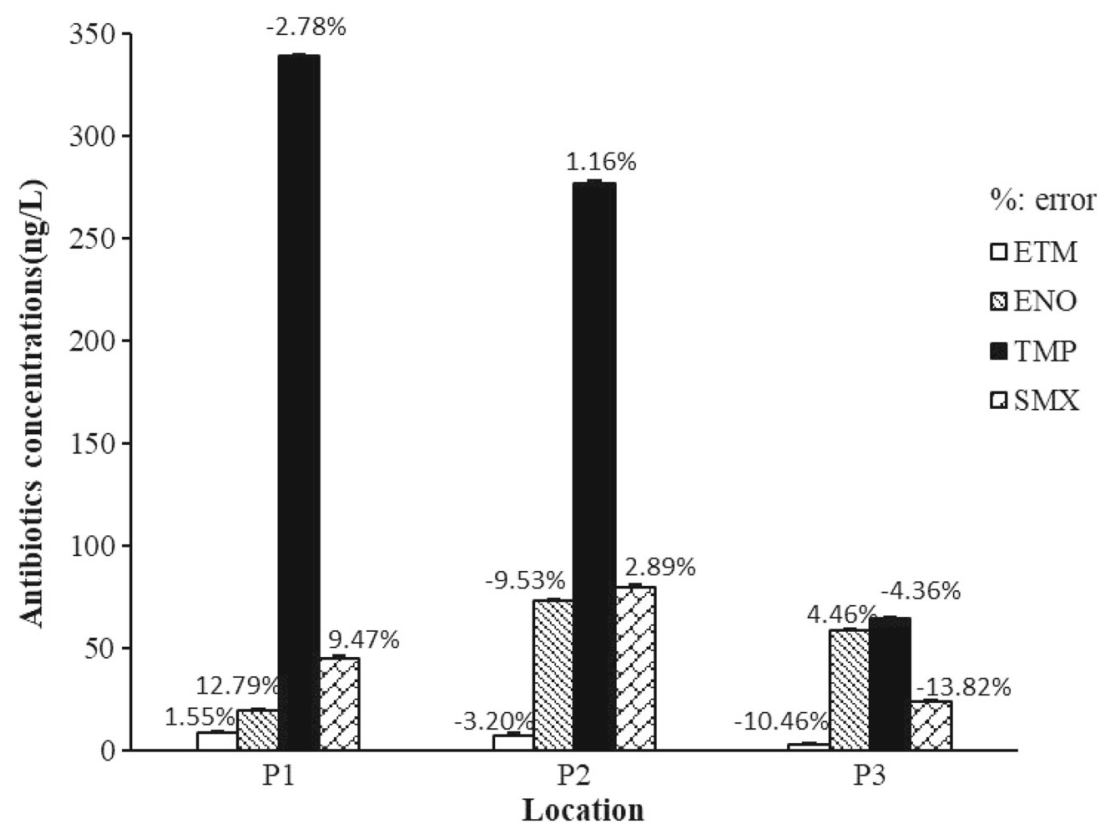


Fig. 7 The sensitivity test of $\tau$

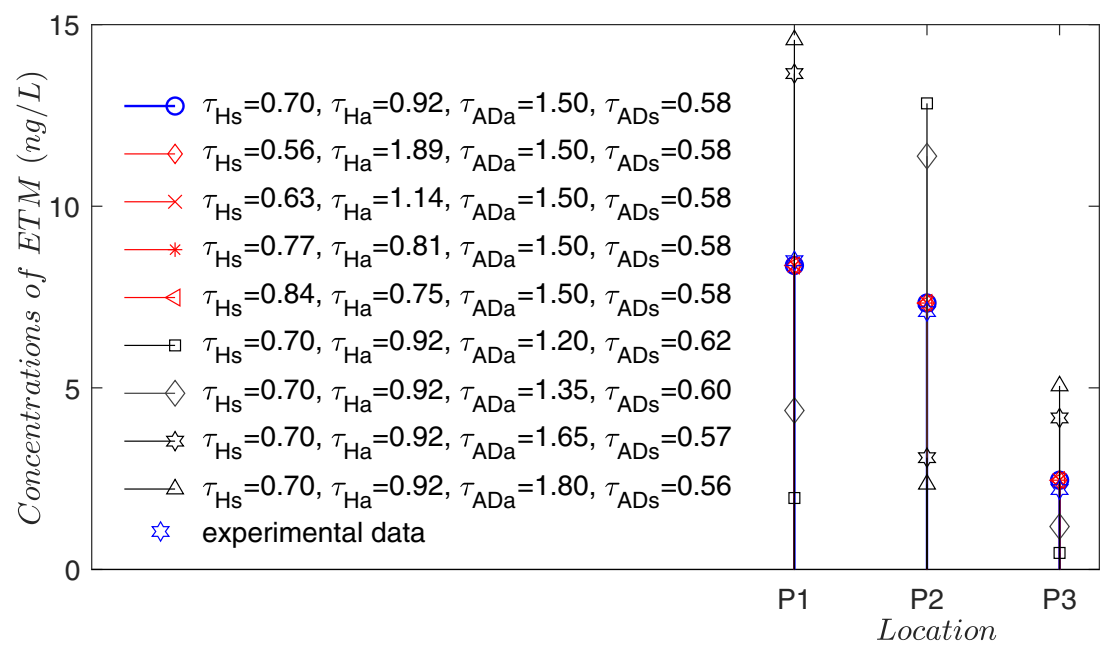

local seafood will increase by 2000 tons, and the cultivated area will increase by $50,000 \mathrm{~m}^{2}$. As a consequence, based on the CPFX concentration data of Zhang et al. (2012) collected in 2012, the concentrations of CPFX are expected to be $35 \mathrm{ng} / \mathrm{L}, 75 \mathrm{ng} / \mathrm{L}$, and $30 \mathrm{ng} / \mathrm{L}$ in the mariculture areas located at M1, M2, and M3 (see Fig. 1), respectively.

\section{Results and discussion}

\section{Model validation and analysis}

A TRT-LBM model is developed and used to simulate the fate of antibiotics in the Laizhou Bay. The dispersion coefficients, the symmetric and asymmetric relaxation times are calibrated in the model. The hydrodynamic model can produce the reliable hydrodynamic processes (Fig. 4), which is the basis of the ADR model. And the fractional errors (Fig. 6) based on comparison of simulation results and experimental data vary from -13.82 to $12.79 \%$, which illustrates that the model is sufficiently accurate to solve the problem of antibiotic transport. The simulation shows that the antibiotics are heavily polluted in the coastal area (P1, P2, and P3 in Fig. 1). Among the four high-detected antibiotics from Fig. 6, TMP is the highest one in the coastal water varying from 64.095 to $338.924 \mathrm{ng} / \mathrm{L}$. The lowest values from ETM still reach the level of nanogram per liter. The hydrodynamic model facilitates the transport of antibiotics in the Laizhou Bay. However, the bay is a semi-enclosed location and has poor water exchange with the open sea, increasing contamination in the inner bay and leading to high-level environmental risks. Fewer than 5 days are needed to simulate 44-day transport in scenario 1, highlighting the efficiency of the proposed model, which is a superiority in practical applications. All cases involved in this study are characterized by $R e<200$ ( $R e$ is the Reynolds number), within the laminar flow range, and the model can be calculated stably. However, the proposed model also has limitations. Although the coupled model in this study includes reaction

Fig. 8 The sensitivity test of $K_{i j}$

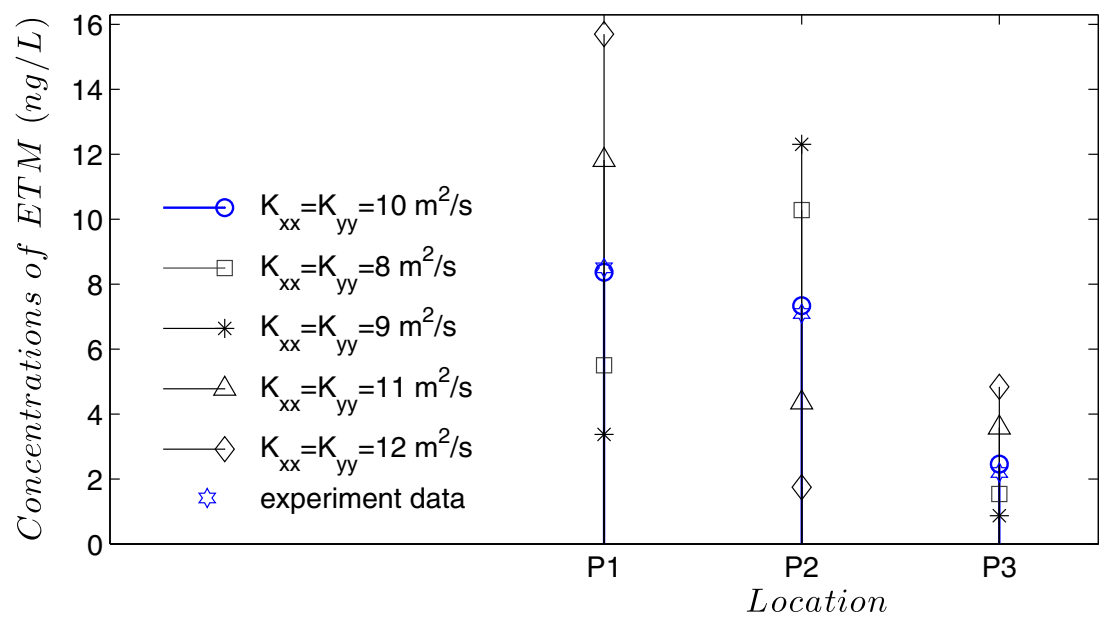


Fig. 9 The transport process of ENO in the Laizhou Bay

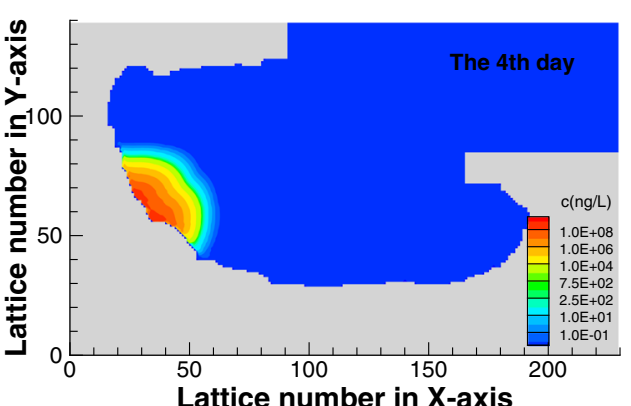

(a)

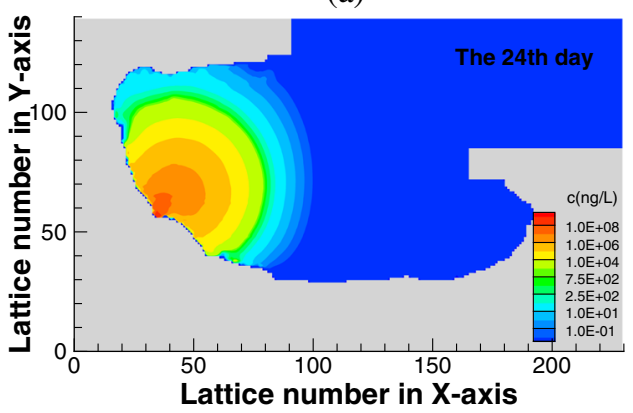

(c)

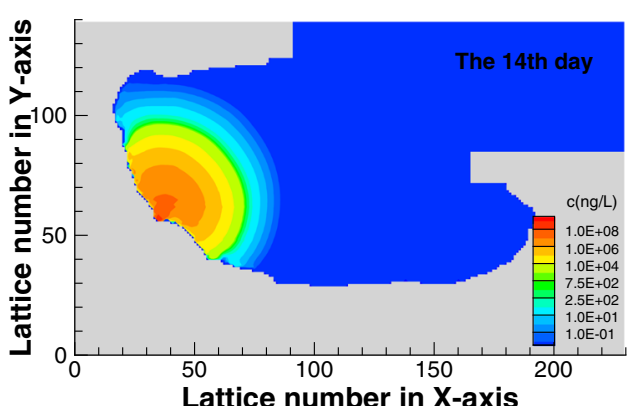

(b)

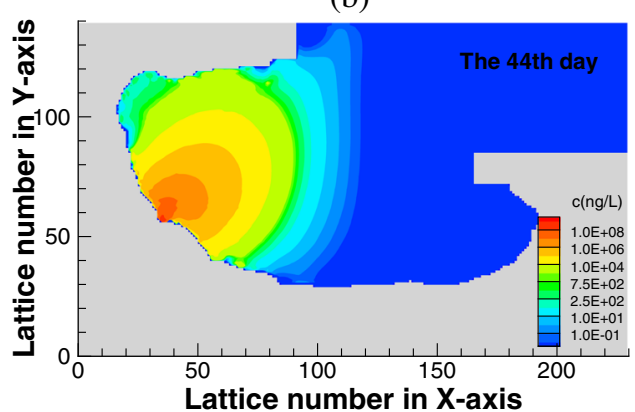

(d) properties through the coefficients of degradation rates, physicochemical processes (e.g., organic carbon normalized partition coefficients) are not considered.

\section{The implications from sewage treatment plants}

A main source of the antibiotics in the Laizhou Bay is from the sewage treatment plants, and the antibiotics enter into the bay by the adjacent estuaries. Figure 9 shows the transport process of ENO in the Laizhou Bay over 44 days. The polluted area develops rapidly with the diffusion of ENO. Figure 9 a suggests that a high level of ENO pollution occurs at the initial stage, with the concentrations being even greater than $1000 \mathrm{ng} / \mathrm{L}$ near the estuaries. Then, the contaminated zone presents a trend of moving farther from the coast (Fig. 9b). Figure $9 \mathrm{c}$ shows the increasing polluted area and the border of contaminated area with over $250 \mathrm{ng} / \mathrm{L}$. On the forty-fourth day (see Fig. 9d), the pollution covers almost the whole inner bay. The areas with ENO $>750 \mathrm{ng} / \mathrm{L}$ are dominant in the Laizhou Bay, and the transport has already reached the northwestern coastline. Furthermore, the area with the concentration lower than $250 \mathrm{ng} / \mathrm{L}$ grows towards the outer bay. The majority of estuaries are located in the northwestern portion of the bay, resulting in the higher pollutant concentrations and longer duration in the northwestern area. Additionally, the concentrations at the selected locations are lower than those near the river estuaries, which may mainly result from seawater dilution caused by river discharge into the bay (Zou et al. 2011).
Sewage treatment plant is the place to remove antibiotics as well as a main source of antibiotics in the aquatic environment. Currently, urban sewage treatment plants emphasize the removal of conventional pollutants like nitrogen and phosphorus, which can be effectively removed by contemporary technologies. However, the removal rate of antibiotics by the technologies is usually very low, or even negative. Therefore, the development of wastewater pretreatment and deep treatment technology for antibiotics is imperative. Moreover, based on the conditions in the Laizhou Bay, the testing standard of antibiotics in sewage should be established to provide a basis for removing antibiotics in sewage treatment system. Figure 9 shows

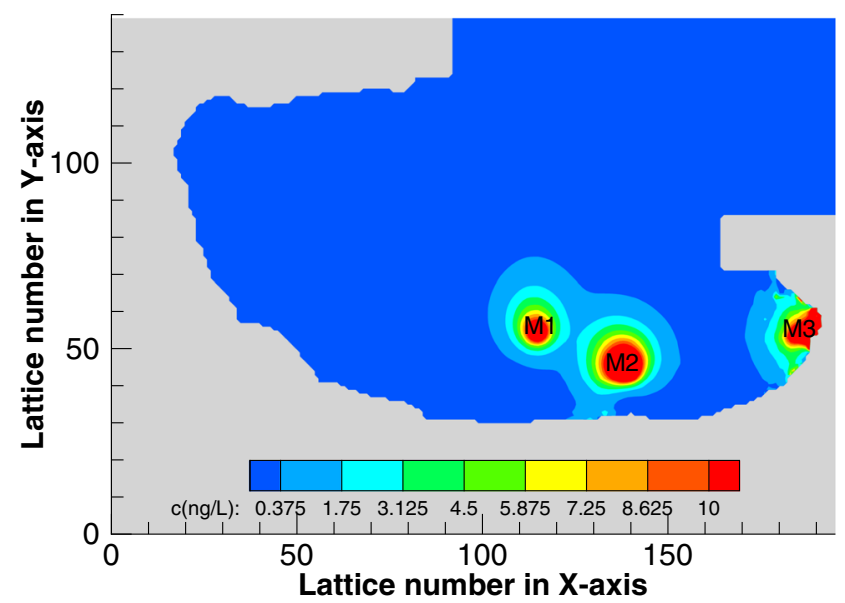

Fig. 10 Distribution of CPFX in the Laizhou Bay after 15 days 
Fig. 11 The CPFX

concentrations change over time in $\mathrm{P} 4, \mathrm{P} 5$, and $\mathrm{P} 6$

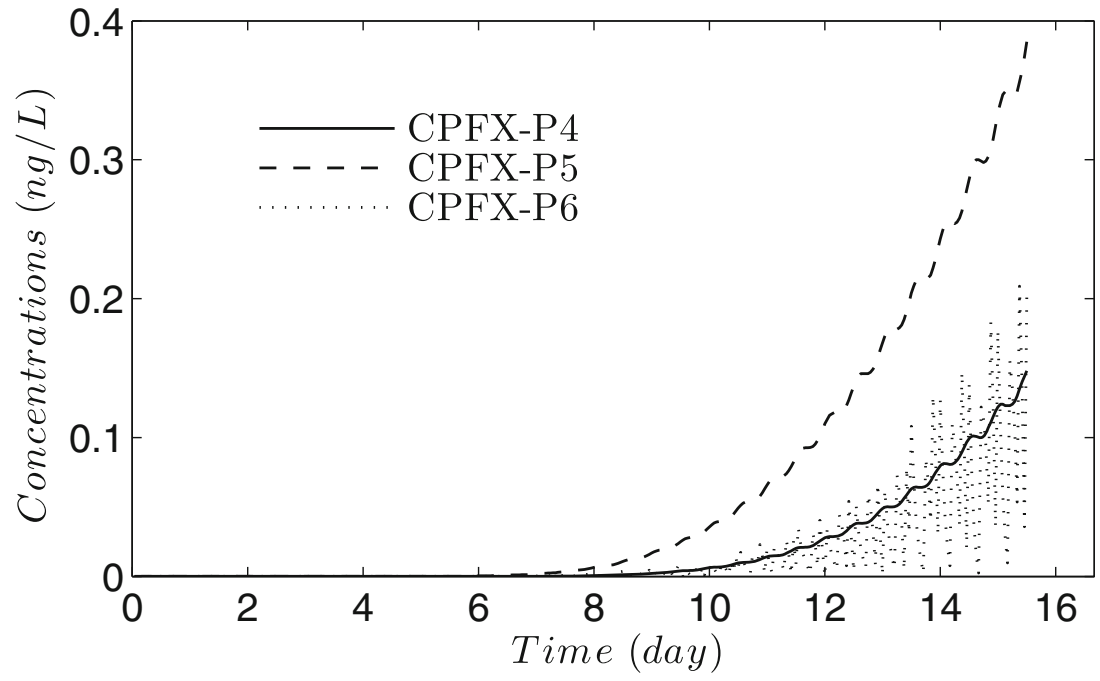

the significant consequences if these sewage treatment plants near the Guangli and Xiaoqing Rivers are to be left unregulated. Therefore, local government should accelerate the establishment of antibiotics emission regulation and management system, to strictly limit the amounts of antibiotics in drained sewage in accordance with the existing regulation and system. It is also important to investigate and deal with the violations according to law, thereby greatly reducing the discharge of antibiotics from sewage treatment plants. They are the main sources of antibiotics, having significant impacts on the aquatic environment.

\section{The implications from mariculture}

Another main source of the antibiotics in the Laizhou Bay is mariculture. The distribution of CPFX in the Laizhou Bay after 15 days is plotted in Fig. 10. CPFX is transported around the mariculture area annually. In the vicinity of $\mathrm{M} 1$, the concentration can reach $10 \mathrm{ng} / \mathrm{L}$. Given sufficient time, the concentrations near M1 will be higher due to the accumulation of antibiotics, and CPFX can have effects on the outer bay via further transport. The CPFX near M2 transported widely due to its high initial concentrations. There is an overlap between M1 and M2 regions where the concentration is lower than $2.3 \mathrm{ng} / \mathrm{L}$. To the south of $\mathrm{M} 2$, the CPFX can reach the near-shore area with more than $1 \mathrm{ng} / \mathrm{L}$ CPFX. The concentrations at the shoreline (M3) nearby are slightly higher than $10 \mathrm{ng} / \mathrm{L}$. At the same time, owing to the location of the M3 in the bay, the high contaminated area (more than $10 \mathrm{ng} / \mathrm{L}$ ) arrives the adjacent coastal area resulting in a high risk of the southeastern living quarters. The CPFX concentrations vary with time at P4, P5, and P6 (see Fig. 1), as shown in Fig. 11. All these curves indicate an increasing trend, and the dashed line for P5 grows rapidly. The fluctuation of these three lines results from the periodic tides. For example, P6 is very close to the shore and is thus governed by the dry-wet boundary, leading to stronger fluctuation in the dotted line in Fig. 11. In the numerical model, the concentration is set to zero when the grid becomes dry.

There are still irrationalities in production, sale and usage of maricultural antibiotics in China. The supervision is far from enough and many procedures need to be improved. Figure 10 shows the polluted estimation of the antibiotics due to the increasing mariculture in future five years. It describes the serious problems of chronic health harm and aquatic environment destruction caused by residual antibiotics from mariculture without constraints. Therefore, local government should improve the administrative supervision and management system for fishery drugs, and then conduct scientific management in aquaculture. In particular, the maximum residue limit standards and testing standards for fishery drugs should be formulated; the management of the production and sale of fishery drugs should be strengthened; and the abuse of fishery drugs should be penalized.

\section{Conclusion}

The Laizhou Bay in China encounters serious antibiotic pollution issues following the prosperous industrialization and fishery in recent years. In this study, a 2D numerical TRT-LBM coupling hydrodynamic and ADR modules is used to simulate the transport and distribution of antibiotics in the Laizhou Bay. The comparison shows the consistencies among simulations, results in reference and experimental data, verifying the applicability of the model. Subsequently, the model is used to study two scenarios, involving 
the discharge from local sewage treatment plants and mariculture. Based on the prediction, the antibiotic pollution will become more serious in the Laizhou Bay, requiring more effective environmental management policies to improve local aquatic environment.

Funding information This work was supported by the National Key R\&D Program (2018YFC1406404) and the National Natural Science Foundation of China (51779011).

\section{Appendix: The Dry-wet boundary}

When it comes to the dry-wet boundary, two cases with $n<4$ and $n \geq 4$ are included, $n$ is the number of the adjacent wet nodes of a dry node (Fig. 12). The undetermined $f_{\alpha}$ at dry nodes moving to wet nodes can be calculated by Eq. (21) (Liu et al. 2016). Take Fig. 12a for instance, $f_{1}, f_{2}$, and $f_{8}$ at $t+\Delta t$ can be calculated from

$$
\begin{array}{r}
f_{\alpha}=f_{\alpha}^{(0)}-\tau_{a} \Delta t\left[\left(\frac{\partial}{\partial t}+e_{\alpha j} \frac{\partial}{\partial x_{j}}\right) f_{\alpha}^{(0)}+3 \omega_{\alpha} \frac{g \bar{h} e_{\alpha j} \partial Z_{b}}{e^{2} \partial x_{j}}-3 \omega_{\alpha} \frac{e_{\alpha i} F_{i}}{e^{2}}\right]+ \\
\tau_{a}^{2}(\Delta t)^{2}\left(1-\frac{1}{2 \tau_{a}}\right)\left[\left(\frac{\partial}{\partial t}+e_{\alpha j} \frac{\partial}{\partial x_{j}}\right)^{2} f_{\alpha}^{(0)}+3 \omega_{\alpha} \frac{g e_{\alpha j}}{e^{2}}\left(\frac{\partial h}{\partial t}+e_{\alpha j} \frac{\partial h}{\partial x_{j}}\right) \frac{\partial Z_{b}}{\partial x_{j}}+\right. \\
\left.3 \omega_{\alpha} \frac{g \bar{h}_{\alpha i} e_{\alpha_{\alpha j} \partial^{2} Z_{b}}}{e^{2} \partial x_{i} \partial x_{j}}-3 \omega_{\alpha} \frac{e_{\alpha j}}{e^{2}}\left(\frac{\partial F_{i}}{\partial t}+e_{\alpha j} \frac{\partial F_{i}}{\partial x_{j}}\right)\right] .
\end{array}
$$

However, there are still undetermined $f_{3}$ and $f_{7}$, which can be calculated by the average value of its adjacent nodes for $n<4$ as Eq. 22. If $n \geq 4$ (Fig. 12b), only undetermined term $f_{0}$ can be obtained by Liu et al. (2016)

$f_{\alpha}=\frac{1}{8} \sum_{\alpha=1}^{8} f_{\alpha}\left(x+e_{\alpha} \Delta t\right)$.

Therefore, the computing procedure can be summarized as:

i. Initialize the $h, u$, and $v$ in the wet area;

ii. Calculate $f_{\alpha}^{e q}$ from Eq. (11);

iii. In case of $f_{\alpha}>0$ at the dry grid next to the drywet interface (the flow at a wet node has enough momentum to arrive at the adjacent dry node), $f_{\alpha}$ at dry grid can be obtained by Eqs. (21) and (22). Aside from this case, the bounce-back boundary is implemented to determining $f_{\alpha}$;

iv. Calculate $f_{\alpha}$ using Eq. (4);

v. Utilize step iii to obtain the undetermined $f_{\alpha}$ at the dry grid at $t+\Delta t$;

vi. Update $h, u$, and $v$ in the wet area with Eqs. (12)-(13);

vii. Go back to step ii and repeat steps iii-vi until getting the results in the required time.

Similarly, for the ADR model, $g_{1}, g_{2}$, and $g_{8}$ at $t+\Delta t$ can be calculated by

$$
\begin{aligned}
& g_{\alpha}=g_{\alpha}^{(0)}-\tau_{a} \Delta t\left[\left(\frac{\partial}{\partial t}+s_{\alpha j} \frac{\partial}{\partial x_{j}}\right) g_{\alpha}^{(0)}-\frac{S_{c}}{b}\right]+ \\
& \tau_{a}^{2}(\Delta t)^{2}\left(1-\frac{1}{2 \tau_{a}}\right)\left[\left(\frac{\partial}{\partial t}+s_{\alpha j} \frac{\partial}{\partial x_{j}}\right)^{2} g_{\alpha}^{(0)}-\frac{S_{c}}{b}\right],
\end{aligned}
$$

Fig. 12 Sketch of the dry-wet interface ( $d$ and $w$ represent dry and wet grids, respectively): a $n<4 ; \mathbf{b} n \geq 4$. (a)
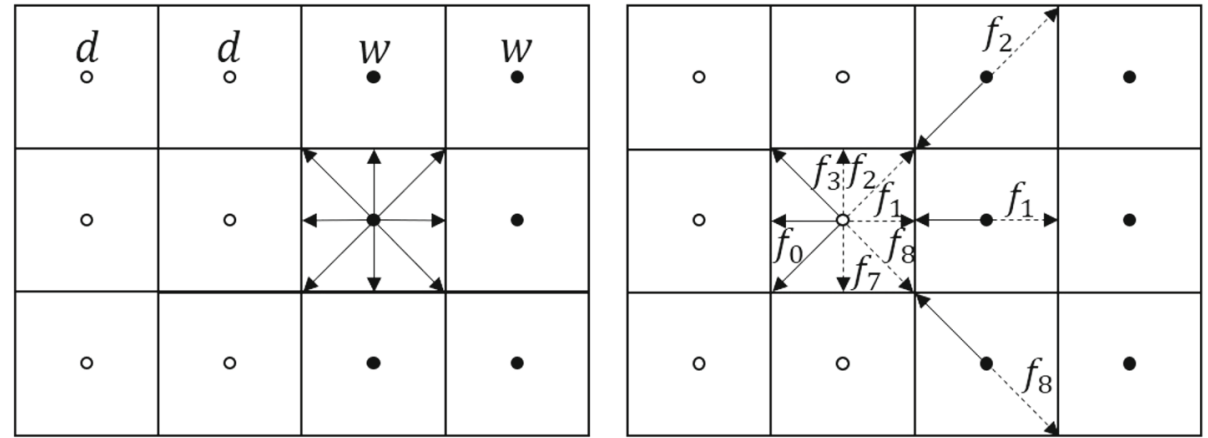

(b)

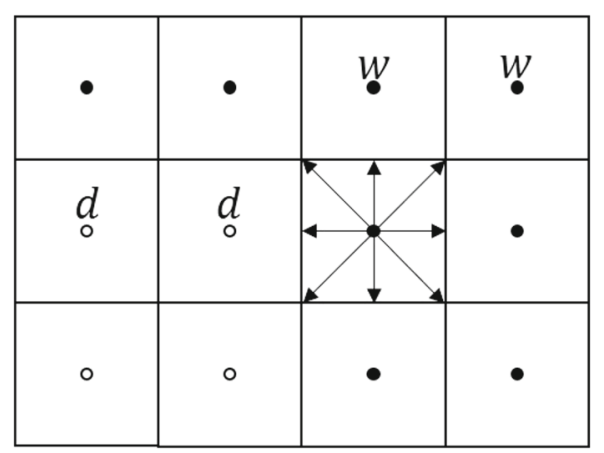

$t$

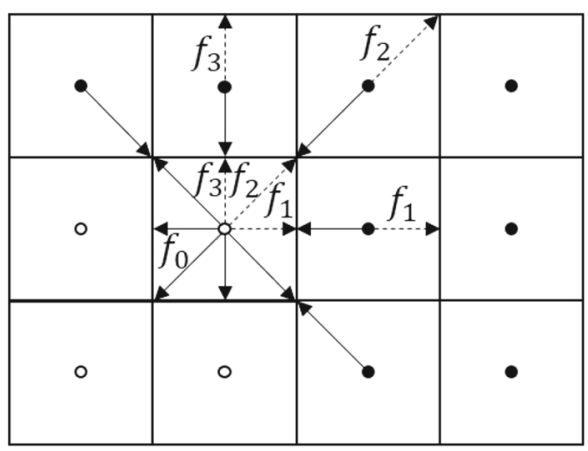

$t+\Delta t$ 
and

$g_{\alpha}^{(0)}=0, \frac{\partial g_{\alpha}^{(0)}}{\partial t}=\frac{g_{\alpha}^{(0)}(t)-g_{\alpha}^{(0)}(t-1)}{\Delta t}=0$,

$g_{0}$ can be calculated from

$g_{0}=\frac{1}{8} \sum_{\alpha=1}^{8} g_{\alpha}\left(x+s_{\alpha} \Delta t\right)$.

\section{References}

Andreozzi R, Raffaele M, Nicklas P (2003) Pharmaceuticals in STP effluents and their solar photodegradation in aquatic environment. Chemosphere 50(10):1319-30

Chen H, Jing L, Teng Y, Wang J (2018) Multimedia fate modeling and risk assessment of antibiotics in a water-scarce megacity. Journal of Hazardous Materials 348:75-83

Chi J, Yang Q (2012) Effects of Potamogeton crispus L. on the fate of phthalic acid esters in an aquatic microcosm. Water Research 46(8):2570-2578

Du J, Zhao H, Chen J (2015) Simultaneous determination of 23antibiotics in mariculture water using solid-phase extraction and high performance liquid chromatography-tandem mass spectrometry. Chinese J Chromatograph 33(4):348

Fick J, Söderström H, Lindberg R, Phan C, Tysklind M, Larsson D (2010) Contamination of surface, ground, and drinking water from pharmaceutical production. Environmental Toxicology \& Chemistry 28(12):2522-2527

Ginzburg I (2005) Equilibrium-type and link-type lattice Boltzmann models for generic advection and anisotropic-dispersion equation. Adv Water Resources 28(11):1171-1195

Ginzburg I, Verhaeghe F, D'Humieres D (2008) Two-relaxationtime lattice Boltzmann scheme: about parametrization, velocity, pressure and mixed boundary conditions. Commun Comput Phys 3(3):427-478

Gothwal R, Thatikonda S (2018) Mathematical model for the transport of fluoroquinolone and its resistant bacteria in aquatic environment. Environmental Science and Pollution Research 25(21):20439-20452

Hallingsørensen B, Jørgensen E (2000) Algal toxicity of antibacterial agents used in intensive farming. Chemosphere 40(7):731-739

Hallingsørensen B, Nors N, Lanzky P, Ingerslev F, Holten L, Jørgensen S (1998) Occurrence, fate and effects of pharmaceutical substances in the environment-A review. Chemosphere 36(2):357

Holmström K, Gräslund S, Wahlström A, Poungshompoo S, Bengtsson B, Kautsky N (2003) Antibiotic use in shrimp farming and implications for environmental impacts and human health. Int $\mathbf{J}$ Food Sci Technol 38(3):255-266

Kümmerer K (2003) Significance of antibiotics in the environment. Journal of Antimicrobial Chemotherapy 52(1):5-7

Kümmerer K (2009) Antibiotics in the aquatic environment-a reviewPart II. Chemosphere 75(4):435-441

Li C, Lu J, Liu J, Zhang G, Tong Y, Ma N (2016) Exploring the correlations between antibiotics and antibiotic resistance genes in the wastewater treatment plants of hospitals in Xinjiang, China. Environmental Science and Pollution Research 23(15):1511115121

Liu H, Zhang J, Shafiai SH (2016) A second-order treatment to the wet-dry interface of shallow water. J Hydrology 536:514-523

Liu H, Zhang J, Wang H, Ding Y, Yi Y (2017) Numerical modeling of the tidal wave run-up and the eelgrass habitat at the Laizhou Bay. Ecological Modelling 360:378-386
Liu J, Wong M (2013) Pharmaceuticals and personal care products (PPCPs): A review on environmental contamination in China. Environment International 59(3):208-224

Lv T, Sun B, Wang J, Jin Y, He X, Yu H, qing Ma Y (2017) The hydrodynamic environment variability of Laizhou bay response to the marine engineering. Marine Environmental Science 36(4):571-577

Meng L, Yang B, Xue N (2015) A review on environmental behaviors and ecotoxicology of fluoroquinolone antibiotics. Asian Journal of Ecotoxicology 10(2):76-88

Min M, Lu G (2013) Antibiotics in water environment. Chem Bioeng 30(11):19-22

Peng Y, Zhang J, Zhou J (2016) Lattice Boltzmann model using two relaxation times for shallow-water equations. Journal of Hydraulic Engineering 142(2):06015017

Ryan C, Tan D, Arnold W (2011) Direct and indirect photolysis of sulfamethoxazole and trimethoprim in wastewater treatment plant effluent. Water Res 45(3):1280-6

Shi H, Wang XC, Li Q, Jiang S (2016) Degradation of typical antibiotics during human feces aerobic composting under different temperatures. Environmental Science and Pollution Research 23(15):15076-15087

Torniainen K, Mattinen J, Askolin C, Tammilehto S (1997) Structure elucidation of a photodegradation product of ciprofloxacin. Journal of Pharmaceutical \& Biomedical Analysis 15(7):887894

Xiao J, Liu L, Zou S (2008) Photodegradation behavior of representative macrolide antibiotics in water environment. Guangzhou Chemistry 33(2): $1-5$

$\mathrm{Xu}$ H, Jiang T (1990) Numerical simulation on tidal current and pollutant diffusion in Laizhou Bay. Marine Science Bulletin 9(4):64-72

Yang G, Fan M, Zhang G (2014) Emerging contaminants in surface waters in China - a short review. Environmental Research Letters 9(7):074018

Zhang C (2013) The distribution, migration and transformation of $\mathrm{PhACs}$ in wastewater treatment process. Master's Thesis, Hebei University of Engineering

Zhang L (2016) Optimization of quinolone antibiotics detection method and in water photolysis and hydrolysis characteristics research. Master's Thesis, Jilin Agricultural University

Zhang Q, Ying G, Pan C, Liu Y, Zhao J (2015) Comprehensive evaluation of antibiotics emission and fate in the river basins of China: source analysis, multimedia modeling, and linkage to bacterial resistance. Environment Sci Technol 49(11):67726782

Zhang R, Zhang G, Zheng Q, Tang J, Chen Y, Xu W, Zou Y, Chen X (2012) Occurrence and risks of antibiotics in the Laizhou Bay, China: impacts of river discharge. Ecotoxicology \& Environmental Safety 80(2):208-215

Zhang R, Zhang G, Zheng Q, Tang J, Jun L, Liu X, Zou Y, Chen X, Yang Z (2012) Concentrations and spatial distributions of selected quinolones antibiotics in Laizhou Bay and main rivers flowing into the bay. Marine Environmental Science 31(1):53-47

Zhou J (2004) Lattice Boltzmann methods for shallow water flows. Springer, Berlin

Zhou J (2011) Lattice Boltzmann method for advection and anisotropic dispersion equation. J Appl Mech 78(2):856-875

Zou S, Xu W, Zhang R, Tang J, Chen Y, Zhang G (2011) Occurrence and distribution of antibiotics in coastal water of the Bohai Bay, China: Impacts of river discharge and aquaculture activities. Environmental Pollution 159(10):2913-2920

Publisher's note Springer Nature remains neutral with regard to jurisdictional claims in published maps and institutional affiliations. 